\title{
Prevalence and Drivers of Tobacco use Among Young Men in Sub-Saharan Africa: Evidence from 21 Nationally Representative Surveys
}

Eugene Kofuor Maafo Darteh ( $\nabla$ edarteh@ucc.edu.gh )

University of Cape Coast https://orcid.org/0000-0003-4689-8891

\section{Sanni Yaya}

University of Ottawa Faculty of Health Sciences

Kwamena Sekyi Dickson

University of Cape Coast

Abdul-Aziz Seidu

University of Cape Coast

\section{Research}

Keywords: Tobacco use, young men, sub-Saharan, Africa, Global Health, Public Health

Posted Date: April 28th, 2020

DOI: https://doi.org/10.21203/rs.3.rs-24817/v1

License: (c) (i) This work is licensed under a Creative Commons Attribution 4.0 International License. Read Full License 


\section{Abstract}

Background Tobacco consumption - including smoking, chewing tobacco and snuff has been recognized as a global public health issue and a major cause of premature mortality and morbidity. An annual estimated figure of more than 7 million people dies due to tobacco consumption with more than 6 million of those deaths attributed to direct tobacco use and about 890, 000 resulting from exposure to second-hand smoke. This paper seeks to examine the prevalence and drivers of tobacco use among young men in sub-Saharan Africa.

Methods Using pooled data from the most recent Demographic and Health Survey (DHS) conducted between January 1, 2010, and December 3, 2018, in 21 countries that had data on tobacco use in SSA this paper examines tobacco use among young men in sub-Saharan Africa. A chi-square was conducted at the bivariate level to test for the significance of tobacco use across the socio-demographic characteristics. A binary logistic regression test was conducted at the multi-variate level to estimate the determinants of tobacco use among young people in SSA. The confidence interval for both the bivariate and multivariate tests was $95 \%$.

Results The overall prevalence of tobacco use was 9.34\% (95\% Cl: 7.52-11.16) with the lowest prevalence in Ghana (1.46\%) and the highest in Lesotho (39.19\%). It was also found that those aged 20$24[\mathrm{AOR}=3.080, \mathrm{Cl}=2.840-3.341]$, engaged in unskilled labour [AOR $=2.651, \mathrm{Cl}=2.333-3.012]$, who are widowed/divorced/separated $[A O R=2.747, \mathrm{Cl}=[2.301-3.279]$ and with no religion $[\mathrm{AOR}=1.460, \mathrm{Cl}=$ 1.273-1.676] had higher odds of using tobacco. On the other hand, young, men with secondary [AOR = $0.726, \mathrm{Cl}=0.645-0.818]$ and higher $[\mathrm{AOR}=0.563, \mathrm{Cl}=[0.446-0.710]$ level of education, those in the richest wealth quintile[AOR $=0.758, \mathrm{Cl}=0.660-0.871]$, those in rural areas $[A O R=0.869, \mathrm{Cl}=0.795-$ $0.950]$, and those who read newspaper or magazine at least once a week [AOR $=0.898, \mathrm{Cl}=0.808-0.998]$ had lower odds of tobacco use.

Conclusion Age, level of education, wealth status, working status, marital status, religion and place of residence were statistically significant association with tobacco use among young men in SSA. These socioeconomic factors should be considered when trying to tackle tobacco use in SSA. Specific public health interventions should take into account these socio-economic factors to reduce tobacco use among young people in SSA

\section{Background}

Tobacco consumption which includes smoking, chewing tobacco and snuff has been acknowledged as a universal public health issue and a major cause of untimely mortality and morbidity $[1,2]$. Tobacco consumption kills nearly up to half of its users [3]. Annually, more than 7 million people die due to tobacco consumption [3] More than 6 million of those deaths are attributed to direct tobacco use while around 890,000 are the result of non-smokers being exposed to second-hand smoke [3]. 
Almost all countries in sub-Saharan Africa (SSA) have signed the WHO Framework Convention on Tobacco Control (WHO FCTC) and expressed their willingness of ratifying this convention but the commitment and implementation are varied among countries [3]. Target 3A of the Sustainable Development Goals (SDG) seeks to strengthen the implementation of the WHO FTC in all countries. SSA countries have low rates of taxation on tobacco, weaker smoke-free policies and where there are policies, there are no or minimal enforcement of such policies $[3,4]$. Countries in the sub-region have less strict tobacco advertising laws compared to their colleagues in the high-income countries [5]. Nearly, 80 per cent of the world's more than 1 billion smokers live in low and middle-income countries (LMICs). It is projected that between 2002 and 2030, deaths attributed to tobacco consumption would double in LMICs including SSA [3].

The prevalence of tobacco consumption varies across countries. Screeramare, Pradhan and Sin [6] observed in their study that, in Eastern African tobacco consumption ranged from $12.9 \%$ in Rwanda to $28.5 \%$ in Madagascar. In West Africa, it ranged from $7.6 \%$ in Ghana to $37.7 \%$ in Sierra Leone. The prevalence in Central Africa ranged from $5.4 \%$ in Sao Tome and Principe to $22.4 \%$ in Gabon and for Southern Africa, it ranged from $14.4 \%$ in Swaziland to $34.1 \%$ in Lesotho.

The adverse effect of tobacco use is not limited to smokers but also second-hand smokers. This has led to researchers focusing on the adverse health outcomes and the consequences of tobacco use [7-9]. Much attention has been focused on cigarette smoking [2, 10-14] and creating a dearth of knowledge on the other forms of tobacco use. Also, the focus has been on adult men and women and their socioeconomic inequalities in tobacco use [15-17]. This study, therefore, sought to examine prevalence and drivers of tobacco use among young men in SSA- a group among whom there is a paucity of literature.

\section{Material And Methods}

\section{Data source and sampling of participants}

This study made use of pooled data from the most recent Demographic and Health Survey (DHS) conducted between January 1, 2010, and December 3, 2018, in 21 countries that had data on tobacco use in SSA (see Table 1). The DHS is a nationally representative study undertaken every five years in various LMICs globally. It focuses on maternal and child health by interviewing women in their reproductive age (15-49 years). Aside from the fact that women and children are the principal focus, men aged 15-64 are also interviewed. The surveys adhere to the various best practices and procedures such as sampling, questionnaires, data collection, cleaning, coding and analysis which allows the surveys to be comparable across countries. A two-stage sampling technique was used for the surveys to ensure national representativeness. The initial stage is characterised by the selection of primary sampling units (PSUs) or enumeration areas (EAs) in specific countries. This surveys usually adopt the PSUs or EAS used for the most recent Population and Housing Census. The second level of the sampling is the systematic selection of households from the selected EAs. Afterwards, in-person interviews are conducted in designated households to target populations - women (15-49 years), men (15-64) as well as children 
under five. All men who are usual residents of selected households or visitors who slept in the households on the night before the survey were interviewed. However, for this study, only young men (15-24) for whom there was information on tobacco use were included $(N=48,885)$. Details of the DHS methodology has been extensively described elsewhere $[18,19]$ Data is available freely at https://dhsprogram.com/data/available-datasets.cfm.

Table 1

Description of the study sample

\begin{tabular}{|lll|}
\hline Country (Survey Year) & Sample (N) & Sample (\%) \\
\hline 1. Angola, 2015/16 & 2,448 & 5.01 \\
\hline 2. Burkina Faso, 2010 & 2,065 & 4.22 \\
\hline 3. DR Congo, 2013/14 & 3,029 & 6.2 \\
\hline 4. Congo, 2011/12 & 1,494 & 3.06 \\
\hline 5. Cote D'lvoire, 2011/12 & 1,758 & 3.6 \\
\hline 6. Cameroon, 2011 & 2,749 & 5.62 \\
\hline 7. Gabon, 2012 & 1,915 & 3.92 \\
\hline 8. Ghana, 2014 & 1,507 & 3.08 \\
\hline 9. Gambia, 2013 & 1,610 & 3.29 \\
\hline 10. Kenya, 2014 & 4,710 & 9.63 \\
\hline 11. Comoros, 2012 & 779 & 1.59 \\
\hline 12. Liberia, 2013 & 1,478 & 3.02 \\
\hline 13. Lesotho, 2014 & 592 & 1.21 \\
\hline 14. Mali, 2018 & 985 & 2.01 \\
\hline 15. Nigeria, 2018 & 6,400 & 13.09 \\
\hline 16. Namibia, 2013 & 1,436 & 2.94 \\
\hline 17. Rwanda, 2014/15 & 2,268 & 4.64 \\
\hline 18. Sierra Leone, 2013 & 2,513 & 5.14 \\
\hline 19. Senegal, 2017 & 2,143 & 4.38 \\
\hline 20. Togo, 2013/14 & 1,607 & 3.29 \\
\hline 21. Zambia, 2018 & 5,399 & 11.04 \\
\hline Total & 48,885 & 100.0 \\
\hline
\end{tabular}


Table 2

Socio-demographic characteristics and prevalence of tobacco use among young men in SSA.

\begin{tabular}{|c|c|c|c|c|}
\hline \multirow{2}{*}{$\begin{array}{l}\text { Variables } \\
\text { Age }\left[\chi^{2}=0.002, p<0.001\right]\end{array}$} & \multirow[t]{2}{*}{ Weighted N } & \multirow[t]{2}{*}{ Weighted \% } & \multicolumn{2}{|c|}{$\begin{array}{l}\text { Tobacco use } \\
(9.34 \%)\end{array}$} \\
\hline & & & $\%$ & $95 \% \mathrm{Cl}$ \\
\hline $15-19$ & 27,492 & 56.2 & 3.7 & {$[3.5-3.9]$} \\
\hline $20-24$ & 21,393 & 43.8 & 13.5 & {$[13.0-14.0]$} \\
\hline \multicolumn{5}{|c|}{ Educational level $\left[x^{2}=300.3, p<0.001\right.$} \\
\hline No Education & 5,363 & 11.0 & 11.8 & {$[11.0-12.7]$} \\
\hline Primary & 13,184 & 27.0 & 9.8 & {$[9.3-10.3]$} \\
\hline Secondary & 27,940 & 57.2 & 6.3 & {$[6.0-6.6]$} \\
\hline Higher & 2,399 & 4.9 & 5.7 & {$[4.7-6.8]$} \\
\hline \multicolumn{5}{|c|}{ Wealth Quintile $\left[x^{2}=112.9, p<0.001\right]$} \\
\hline Poorest & 7,479 & 15.3 & 10.1 & {$[9.5-10.7]$} \\
\hline Poorer & 8,326 & 17.0 & 8.6 & {$[8.1-9.2]$} \\
\hline Middle & 9,873 & 20.2 & 7.5 & {$[7.0-8.0]$} \\
\hline Richer & 11,109 & 22.7 & 7.0 & {$[6.6-7.5]$} \\
\hline Richest & 12,097 & 24.8 & 6.3 & {$[5.9-6.8]$} \\
\hline \multicolumn{5}{|c|}{ Occupation $\left[\chi^{2}=1.2002, p<0.001\right]$} \\
\hline Not working & 20,738 & 42.4 & 3.3 & [3.1-3.6] \\
\hline Professional & 1,320 & 2.7 & 7.0 & [5.7-8.6] \\
\hline Clerical & 273 & 0.6 & 12.9 & [9.2-18.0] \\
\hline Sales & 2,979 & 6.1 & 11.0 & {$[9.9-12.1]$} \\
\hline Agriculture & 12,296 & 25.2 & 10.0 & [9.5-10.5] \\
\hline Services & 2,328 & 4.8 & 15.9 & [14.5-17.4] \\
\hline Skilled & 5,292 & 10.8 & 12.4 & [11.5-13.3] \\
\hline Unskilled & 3,659 & 7.5 & 12.7 & [11.6-13.8] \\
\hline
\end{tabular}




\begin{tabular}{|c|c|c|c|c|}
\hline \multirow{2}{*}{\multicolumn{2}{|c|}{$\begin{array}{l}\text { Variables } \\
\text { Weighted } \mathbf{N} \\
\text { Marital Status }\left[x^{2}=1.1002, p<0.001\right]\end{array}$}} & \multirow[t]{2}{*}{ Weighted \% } & \multicolumn{2}{|c|}{$\begin{array}{l}\text { Tobacco use } \\
(9.34 \%)\end{array}$} \\
\hline & & & & \\
\hline Never married & 44,185 & 90.4 & 6.6 & {$[6.4-6.8]$} \\
\hline Married & 2,706 & 5.5 & 18.0 & {$[16.6-19.4$} \\
\hline Cohabiting & 1,528 & 3.1 & 18.5 & {$[16.6-20.5$} \\
\hline Widowed/divorced/separated & 466 & 1.0 & 33.4 & {$[29.3-37.8$} \\
\hline \multicolumn{5}{|l|}{ Religion $\left[x^{2}=175.5, p<0.001\right]$} \\
\hline Christian & 32,396 & 66.3 & 7.2 & {$[7.0-7.5]$} \\
\hline Muslim & 14,199 & 29.1 & 8.2 & {$[7.7-8.6]$} \\
\hline Traditional & 468 & 1.0 & 13.3 & {$[10.6-16.5$} \\
\hline No religion & 1,822 & 3.7 & 15.0 & {$[13.5-16.7$} \\
\hline \multicolumn{5}{|l|}{ Residence $\left[x^{2}=7.3, p<0.01\right]$} \\
\hline Urban & 23,877 & 48.8 & 7.5 & {$[7.2-7.9]$} \\
\hline Rural & 25,008 & 51.2 & 8.2 & {$[7.8-8.5]$} \\
\hline \multicolumn{5}{|c|}{ Frequency of reading newspaper or magazine $\left[x^{2}=55.83, p<0.001\right]$} \\
\hline Not at all & 29,756 & 60.9 & 8.5 & [8.2-8.9] \\
\hline Less than once a week & 8,536 & 17.5 & 7.1 & {$[6.6-7.7]$} \\
\hline At least once a week & 9,440 & 19.3 & 6.4 & {$[5.9-6.9]$} \\
\hline Almost every day & 1,153 & 2.4 & 6.3 & {$[5.0-7.9]$} \\
\hline \multicolumn{5}{|c|}{ Frequency of listening to radio $\left[x^{2}=7.70, p<0.05\right]$} \\
\hline Not at all & 11,233 & 23.0 & 8.5 & {$[8.0-9.0]$} \\
\hline Less than once a week & 8,969 & 18.4 & 7.6 & {$[7.1-8.2]$} \\
\hline At least once a week & 24,578 & 50.3 & 7.7 & [7.4-8.0] \\
\hline Almost every day & 4,105 & 8.4 & 7.7 & {$[6.9-8.6]$} \\
\hline \multicolumn{5}{|c|}{ Frequency of watching television $\left[x^{2}=21.0, p<0.001\right]$} \\
\hline Not at all & 16,839 & 34.5 & 8.6 & {$[8.2-9.0]$} \\
\hline
\end{tabular}




\begin{tabular}{|lllll|}
\hline Variables & Weighted N & Weighted \% & \multicolumn{2}{l|}{ Tobacco use } \\
& & \multicolumn{3}{c|}{ (9.34\%) } \\
\hline Less than once a week & 8,076 & 16.5 & 7.6 & {$[7.0-8.2]$} \\
\hline At least once a week & 17,884 & 36.6 & 7.4 & {$[7.0-7.7]$} \\
\hline Almost every day & 6,086 & 12.5 & 7.5 & {$[6.8-8.2]$} \\
\hline${ }^{*} p<0.05,{ }^{* \star} p<0.01,{ }^{\star \star \star} p<0.001$ & & & & \\
\hline
\end{tabular}


Table 3

Determinants of tobacco use among young men in SSA

\begin{tabular}{|c|c|c|}
\hline \multirow[t]{2}{*}{ Variable } & Model I & Model II \\
\hline & Crude Odds Ratio (COR) & Adjusted Odds Ratio (AOR) \\
\hline Country & 1 & 1 \\
\hline Angola, 2015/16 & {$[1-1]$} & {$[1-1]$} \\
\hline Burkina Faso, 2010 & $2.037 * \star \star[1.683-2.466]$ & $1.623 * * *[1.296-2.034]$ \\
\hline DR Congo, 2013/14 & $2.001 * \star \star[1.672-2.395]$ & $2.080 * * *[1.700-2.545]$ \\
\hline Congo, 2011/12 & $1.531 \star \star \star[1.231-1.904]$ & $1.511 * \star \star[1.197-1.907]$ \\
\hline Cote D'Ivoire, 2011/12 & $2.061 \star \star \star[1.693-2.509]$ & $1.622 * \star *[1.305-2.016]$ \\
\hline Cameroon, 2011 & $0.898[0.726-1.111]$ & $0.844[0.674-1.058]$ \\
\hline Gabon, 2012 & $2.278 \star \star \star ~[1.884-2.755]$ & $2.282^{\star * \star}[1.851-2.812]$ \\
\hline Ghana, 2014 & $0.206 * \star \star[0.132-0.321]$ & $0.202^{\star \star \star}[0.129-0.319]$ \\
\hline Gambia, 2013 & $1.434 * \star[1.154-1.783]$ & $1.488 * *[1.147-1.931]$ \\
\hline Kenya, 2014 & $0.863[0.713-1.044]$ & $0.769 *[0.621-0.951]$ \\
\hline Comoros, 2012 & $1.575^{\star \star \star}[1.211-2.048]$ & $1.804 * \star \star[1.336-2.438]$ \\
\hline Liberia, 2013 & $0.277 * \star \star[0.187-0.411]$ & $0.250 * \star \star * 0.167-0.373]$ \\
\hline Lesotho, 2014 & $6.953 * \star \star[5.698-8.485]$ & $5.140 \star \star \star ~[4.115-6.420]$ \\
\hline Mali, 2018 & 1.061 [0.805-1.398] & 1.002 [0.734-1.368] \\
\hline Nigeria, 2018 & $0.367 * \star \star[0.297-0.455]$ & $0.411^{\star \star \star}[0.322-0.525]$ \\
\hline Namibia, 2013 & $2.040 \star \star \star ~[1.660-2.507]$ & $2.262^{\star \star \star}[1.806-2.833]$ \\
\hline Rwanda, 2014/15 & $0.426 * \star \star[0.321-0.564]$ & $0.356 * \star \star * 0.265-0.478]$ \\
\hline Sierra Leone, 2013 & 1.19 [0.970-1.458] & $1.375^{\star *}[1.079-1.751]$ \\
\hline Senegal, 2017 & $1.471^{\star \star \star}[1.202-1.799]$ & $1.316 *[1.028-1.686]$ \\
\hline Togo, 2013/14 & $0.361^{\star \star \star}[0.257-0.508]$ & $0.369 * * *[0.260-0.523]$ \\
\hline Zambia, 2018 & $1.001[0.834-1.200]$ & 1.139 [0.937-1.384] \\
\hline Age & 1 & 1 \\
\hline
\end{tabular}

Exponentiated coefficients; $95 \%$ confidence intervals in brackets ${ }^{*} p<0.05,{ }^{* \star} p<0.01,{ }^{* \star} p<0.001$ 


\begin{tabular}{|c|c|c|}
\hline \multirow[t]{2}{*}{ Variable } & \multirow{2}{*}{$\begin{array}{l}\text { Model I } \\
\text { Crude Odds Ratio (COR) }\end{array}$} & \multirow{2}{*}{$\begin{array}{l}\text { Model II } \\
\text { Adjusted Odds Ratio (AOR) }\end{array}$} \\
\hline & & \\
\hline $15-19$ & {$[1-1]$} & {$[1-1]$} \\
\hline $20-24$ & $3.860 \star \star \star[3.595-4.145$ & $3.080 \star \star \star ~[2.840-3.341]$ \\
\hline Educational level & 1 & 1 \\
\hline No Education & {$[1-1]$} & {$[1-1]$} \\
\hline Primary & $0.822 \star \star \star ~[0.749-0.903]$ & $1.094[0.980-1.220]$ \\
\hline Secondary & $0.515^{\star \star \star}[0.471-0.564]$ & $0.726^{\star \star \star}[0.645-0.818]$ \\
\hline Higher & $0.466 * \star \star[0.381-0.569]$ & $0.563 * \star \star[0.446-0.710]$ \\
\hline Wealth status & 1 & 1 \\
\hline Poorest & {$[1-1]$} & {$[1-1]$} \\
\hline Poorer & $0.852 * \star \star[0.775-0.936]$ & $0.853^{\star *}[0.774-0.941]$ \\
\hline Middle & $0.737 \star \star \star ~[0.670-0.812]$ & $0.806 * \star \star[0.727-0.894]$ \\
\hline Richer & $0.688 * \star \star[0.624-0.758]$ & $0.761 * \star \star[0.677-0.855]$ \\
\hline Richest & $0.616 * \star \star[0.556-0.681]$ & $0.758 * \star \star[0.660-0.871]$ \\
\hline Working status & 1 & 1 \\
\hline Not working & {$[1-1]$} & {$[1-1]$} \\
\hline Professional & $2.142 \star \star \star ~[1.702-2.697]$ & $1.377 * \star[1.087-1.745]$ \\
\hline Clerical & $4.080 * \star \star[2.830-5.882]$ & $2.097 \star \star \star ~[1.446-3.042]$ \\
\hline Sales & $3.429 * \star \star[2.999-3.920]$ & $2.082^{\star \star \star}[1.807-2.398]$ \\
\hline Agriculture & $3.107 * \star \star[2.835-3.406]$ & $1.888^{\star \star \star}[1.698-2.100]$ \\
\hline Services & $5.087 * \star \star[4.474-5.784]$ & $2.308 * \star \star[2.004-2.658]$ \\
\hline Skilled & $3.893 * \star \star[3.490-4.343]$ & $2.349 \star \star \star ~[2.081-2.651]$ \\
\hline Unskilled & $4.003 \star \star \star ~[3.554-4.507]$ & $2.651 \star \star \star ~[2.333-3.012]$ \\
\hline Marital status & 1 & 1 \\
\hline Never married & {$[1-1]$} & {$[1-1]$} \\
\hline Married & $2.898 * \star \star[2.633-3.190]$ & $1.276 \star \star \star ~[1.147-1.420]$ \\
\hline \multicolumn{3}{|c|}{ Exponentiated coefficients; $95 \%$ confidence intervals in brackets } \\
\hline \multicolumn{3}{|c|}{${ }^{\star} p<0.05,{ }^{\star \star} p<0.01,{ }^{\star \star \star} p<0.001$} \\
\hline
\end{tabular}




\begin{tabular}{|c|c|c|}
\hline \multirow[t]{2}{*}{ Variable } & Model I & Model II \\
\hline & Crude Odds Ratio (COR) & Adjusted Odds Ratio (AOR) \\
\hline Cohabiting & $2.990 \star \star \star ~[2.648-3.375]$ & $1.407 \star \star \star ~[1.231-1.608]$ \\
\hline Widowed/divorced/separated & $5.955^{\star \star \star}[5.069-6.996]$ & $2.747 \star \star \star ~[2.301-3.279]$ \\
\hline Religion & 1 & 1 \\
\hline Christian & {$[1-1]$} & {$[1-1]$} \\
\hline Muslim & $1.132 \star \star \star ~[1.055-1.215]$ & $1.004[0.892-1.130]$ \\
\hline Traditional & $1.899 \star \star \star ~[1.496-2.409]$ & $1.296 *[1.006-1.670]$ \\
\hline No religion & $2.168 * \star \star[1.917-2.451]$ & $1.460 \star \star \star ~[1.273-1.676]$ \\
\hline Residence & 1 & 1 \\
\hline Urban & {$[1-1]$} & {$[1-1]$} \\
\hline Rural & $1.092 * \star[1.024-1.164]$ & $0.869 * *[0.795-0.950]$ \\
\hline \multicolumn{2}{|c|}{ Frequency of reading newspaper or magazine } & 1 \\
\hline Not at all & {$[1-1]$} & {$[1-1]$} \\
\hline Less than once a week & $0.823^{\star \star \star}[0.753-0.899]$ & $0.987[0.894-1.089]$ \\
\hline At least once a week & $0.740 \star \star \star ~[0.675-0.812]$ & $0.898 *[0.808-0.998]$ \\
\hline Almost every day & $0.725^{\star \star}[0.571-0.921]$ & $0.842[0.654-1.083]$ \\
\hline \multicolumn{2}{|l|}{ Frequency of listening to radio } & 1 \\
\hline Not at all & {$[1-1]$} & {$[1-1]$} \\
\hline Less than once a week & $0.897 *[0.814-0.989]$ & $1.025[0.924-1.137]$ \\
\hline At least once a week & $0.904 *[0.837-0.977]$ & $1.069[0.976-1.170]$ \\
\hline Almost every day & $0.906[0.797-1.030]$ & $1.061[0.911-1.236]$ \\
\hline \multicolumn{2}{|c|}{ Frequency of reading newspaper or magazine } & 1 \\
\hline Not at all & {$[1-1]$} & {$[1-1]$} \\
\hline Less than once a week & $0.875^{\star \star}[0.797-0.960]$ & $1.005[0.909-1.111]$ \\
\hline At least once a week & $0.854 * \star \star[0.792-0.920]$ & $1.026[0.932-1.129]$ \\
\hline Almost every day & $0.863^{* *}[0.775-0.961]$ & $0.964[0.822-1.130]$ \\
\hline \multicolumn{3}{|c|}{ Exponentiated coefficients; $95 \%$ confidence intervals in brackets } \\
\hline \multicolumn{3}{|l|}{${ }^{\star} p<0.05,{ }^{\star \star} p<0.01,{ }^{\star \star \star} p<0.001$} \\
\hline
\end{tabular}




\begin{tabular}{|lll|}
\hline Variable & $\begin{array}{l}\text { Model I } \\
\text { Crude Odds Ratio (COR) }\end{array}$ & $\begin{array}{l}\text { Model II } \\
\text { Adjusted Odds Ratio (AOR) }\end{array}$ \\
\hline Observations & 48885 \\
\hline Pseudo R & 0.158 \\
\hline Exponentiated coefficients; 95\% confidence intervals in brackets \\
\hline${ }^{*} p<0.05,{ }^{* \star} p<0.01,{ }^{\star \star \star} p<0.001$ \\
\hline
\end{tabular}

\section{Measurement Of Variables}

The outcome variable employed for this study was tobacco use. It was derived from the questions "do you currently smoke cigarette?" and "what (other) type of tobacco do you currently smoke or use?". Five types of tobacco use were identified: chewing tobacco (yes, no), uses snuff (yes, no), smoke pipe (yes, no), smoke other (yes, no), smoke cigarette (yes, no). The 'Yes' responses were coded ' 1 ' and the 'No' responses were coded ' 0 '. An index was created with all the yes and no answers with scores ranging from 0 to 5 . The score 0 was labelled as "non-users" and 1 to 5 was labelled as "users". A dummy variable was generated with ' 0 '=Non-user and $1=$ User (at least used one type of tobacco product).

\section{Independent Variables}

Eleven (11) independent variables were considered in this study. They comprised, country, age, wealth status, religious affiliation, type of occupation, level of education, marital status, place of residence, frequency of watching television, frequency of reading newspaper or magazine, and frequency of listening to radio. Three of these variables were recoded to make them theoretically meaningful and easy interpretation. Marital status was captured as never married $=1$, married $=2$, cohabiting $=3$ and widowed $/$ divorced $/$ separated $=4$. Religious affiliation was recoded as Christian $=1$, Islam $=2$, Traditional and No religion $=3$. Type of occupation was also categorised as: Not working $=1$, Professional $=2$, Clerical $=3$, Sales $=4$, Agriculture $=5$, Services $=6$, Skilled $=7$ and Unskilled $=8$. The choice of these independent variables was based on previous studies $[6,11-17]$ that found them to be statistically significantly associated with tobacco use as well as their availability in the DHS dataset.

\section{Analytical Procedure}

The dataset was pooled to generate a total sample of 48,885 . At the first step of the analyses, we computed the proportion of young men who use tobacco in the 21 sub-Saharan African (SSA) countries. The syntax "metan" in STATA version 14.2 was used to generate forest plots which showed the prevalence of tobacco use in individual countries and its corresponding weight, as well as the pooled 
prevalence and its associated $95 \%$ confidence intervals (Cls). A test of heterogeneity showed a high level of inconsistency $\left(I^{2}>50 \%\right)$ thus necessitating the use of a random effect model in the meta-analysis (see Fig. 1). Afterwards, we calculated tobacco use across the socio-demographic characteristics with their significance levels and chi-square $\left[\chi^{2}\right]$ values. The explanatory variables which showed statistical significance with tobacco use $(p<0.05)$ from the chi-square test, were moved to the regression analysis stage to estimate the association between explanatory variables and the dependent variable. 口Specifically, the complementary log-log (Clog-log) link function was used because the outcome variable was unevenly distributed [20]. The results were presented as crude odds ratios (CORs) and adjusted odds ratios (AORs) with their Cls. The statistical significance level was set at $p<0.05$. Hosmer-Lemeshow test was adopted to test the appropriateness of the model specification. Multicollinearity test was also done using the variance inflation factor (Mean VIF $=1.32$, Maximum VIF $=1.70$, Minimum $=1.07$ ). Weighted frequencies were generated while the survey command in STATA was used to account for the complex nature of the data in the regression analyses to produce unbiased robust standard errors.

\section{Ethical Approval}

The DHS surveys obtain ethical clearance from the Ethics Committee of ORC Macro Inc. as well as Ethics Boards of partner organisations of the various countries such as the Ministries of Health. During each of the surveys, either written or verbal consent was provided by the young men. Since the data was not collected by the authors of this manuscript, official permission was sought from MEASURE DHS website and access to the data was provided after our intent for the request was assessed and approved on 3rd April 2019. More details regarding DHS data and ethical standards are available at: http://goo.gl/ny8T6X.

\section{Results}

The prevalence of tobacco usage among young men in each of the 21 SSA countries included in the study are presented in Figure 1. The overall prevalence of tobacco use was 9.34\% (95\% Cl: 7.52-11.16). In Eastern Africa, the prevalence ranged from $5.99 \%$ in Kenya to $6.91 \%$ in Zambia with that of Southern Africa ranging from $13.58 \%$ in Namibia to $39.19 \%$ in Lesotho. Prevalence of tobacco use in Central Africa ranged from $6.22 \%$ in Cameroon to $15.04 \%$ in Gabon. The lowest prevalence was in Ghana (1.46\%) and the highest prevalence in Burkina Faso (13.56\%) for countries in West Africa.

\section{Socio-demographic characteristics and prevalence of tobacco use among young men in SSA}

Table 2 provides a summary of the proportion of tobacco use across the selected socio-demographic characteristics. Young people aged $20-24$ had a greater proportion of tobacco use $[\mathrm{p}=13.5 \%, 95 \% \mathrm{Cl}=13.0$ 14.0]. Tobacco use was highest $[\mathrm{p}=11.8 \%, \mathrm{Cl}=11.0-12.7]$ among those with no formal level of education compared to those with a higher level of education $[p=5.7 \%, 4.7-6.8 \%]$. With wealth quintile, those in the 
poorest wealth quintile had the highest proportion of tobacco use $[p=10.1 \%, 9.5-10.7]$. Young people who are engaged in services had the highest proportion of tobacco use $[p=15.9 \%, 14.5-17.5]$. Young men who were Widowed/divorced/separated recorded the highest proportion of tobacco use [p=33.4\%,29.3-37.8] compared to those who were never married $[p=6.6 \%, 6.4-6.8]$. Those with no religion had the highest proportion $[p=15 \%, 13.5-16.7]$ of tobacco use compared to those who are Christians $[p=7.2 \%, 7.0-7.5]$. The results also show that $[p=8.2 \%, 7.8-8.5]$ of those in rural areas used tobacco. All the explanatory variables showed statistically significant associations with tobacco use among young men in SSA at $95 \%$ confidence interval.

\section{Determinants of tobacco use among young men in SSA}

Table 3 summarizes the factors associated with tobacco use among young men in SSA. Compared to young men in Angola, young men in Lesotho had the highest odds of using tobacco [AOR $=5.140, \mathrm{Cl}=$ 4.115-6.420], $\mathrm{p}<0.001$ ]. However, young men in Ghana had the lowest odds of tobacco use [AOR $=0.202$, $\mathrm{Cl}=0.129-0.319], \mathrm{p}<0.001]$. Those aged 20-24 had higher odds [AOR=3.080, $\mathrm{Cl}=2.840-3.341], \mathrm{p}<0.001]$ of tobacco use compared to those aged $15-19$. Young, men with secondary [AOR=0.726, $\mathrm{Cl}=0.645-0.818]$ and higher [[AOR=0.563, $\mathrm{Cl}=[0.446-0.710], \mathrm{p}<0.001]$ level of education had lower odds of tobacco use compared with those with no formal education. There was an inverse relationship between wealth status and odds of tobacco use. Specifically, those in the richest wealth status had the lowest odds of tobacco use $[A O R=0.758, \mathrm{Cl}=0.660-0.871], \mathrm{p}<0.001]$ compared to those in the poorest wealth quintile. Compared to those who are not working, young men in all the different types of occupations had higher odds of tobacco use in SSA. Specifically, those engaged in unskilled labour had the highest odds of tobacco use $[A O R=2.651, \mathrm{Cl}=2.333-3.012], \mathrm{p}<0.001]$ compared to those who are not working. Young men who are widowed/divorced/separated [AOR=2.747, $\mathrm{Cl}=[2.301-3.279], \mathrm{p}<0.001]$ had the highest odds of tobacco use. In addition, young men with no religion had the highest odds [AOR=1.460, $\mathrm{Cl}=1.273-1.676], \mathrm{p}<0.001$ ] of tobacco use compared with those who are Christians. Those in rural areas [AOR=0.869, $\mathrm{Cl}=0.795-$ $0.950], p<0.01]$ and those who read newspaper or magazine at least once a week [AOR=0.898, $\mathrm{Cl}=0.808$ 0.998], $p<0.05$ ] had lower odds of tobacco use.

\section{Discussion}

The prevalence of tobacco consumption was 9.3 per cent among young men in SSA. This finding is consistent with the findings of Sreeramareddy, Pradhan, and Sin [6] in their study that looked at the prevalence, distribution and social determinants of tobacco use in 30 sub-Saharan African countries. Our study also found out that age, level of education, wealth status, type of occupation, marital status, religion and place of residence had a statistically significant association with tobacco consumption among young men in SSA. Furthermore, our study found out that the odds of tobacco use was higher for the older group compared to the younger age group. This is consistent with previous studies $[6,12,14,21]$. The possible explanation is that older men have a higher level of exposure to tobacco compared to younger men and this may influence the lifestyle and health choice. 
Our study also found out that the likelihood of consuming tobacco reduces as the level of education increases. Young men with a primary, secondary and higher level of education had lesser odds of consuming tobacco as compared with those with no education. This finding is in line with earlier studies $[6,10,14,22]$. The possible explanation would be the educated young men may be exposed to information about the dangerous health risks associated with the consumption of tobacco and are more likely to stay away from consuming tobacco in any form. Education prepares individuals with requisite knowledge and skills so that they can make an informed choice that will positively impact on their health.

Also, we observed that the likelihood of consuming tobacco declines as wealth status increased. For instance, young men with poorer, middle, richer and richest wealth status had a lesser likelihood of using tobacco compared to those from the poorest wealth status. This finding is consistent with the studies of Shrestha et al. [6], Nketiah -Ampoosah, Afful - Mensah and Ampaw [10] and Abdulrahim and Jawad [23]. Our study found a significant association between the type of occupation and tobacco use. Young men who were working had a higher likelihood of using tobacco compared to those who were not working. For instance, those who worked in sales, agriculture, skilled and unskilled labour had higher odds than those who were not working. This finding is consistent with the findings of Fernando et al. [24], Wang et al. [22], Dickson and Ahinkorah [14] and Doku, Darteh \& Kumi-Kyereme, [12]. This may be attributed to the fact that those who are working would have the financial power to afford and purchase of tobacco in all its forms. Work status comes with its social networking and work-related stress and traumas and this can have an influence in health choice and the consumption of tobacco. People may use tobacco to be accepted in a certain social space, whiles others may consume tobacco to destress from work-related traumas and stress.

Our study also found out that young men who were widowed/divorced/separated had a higher odd of using tobacco compare to those who were never married. This finding is consistent with the findings of Ramsey et. al. [25], Dickson and Ahinkorah [12] when they found out that formerly married men had a higher likelihood of using tobacco compare to those who were currently not married. This could be ascribed to the stress and psychological trauma that comes with divorce, separation and the loss of loved ones. Young men may turn to the usage of tobacco as a form of coping strategy in those hard times.

It was seen from our study that young men who are associated with the traditional religion and those with no religion had higher odds of using tobacco compared to Christian young men which confirm previous studies $[12,14,22,26]$. Behaviour boundaries and restrictions vary between regions. Religious affiliations are social networks that influence the individual. Theses influences are affected by the religiosity of the individual [27]. Once religious affiliation may promote or restrict their lifestyle and this may affect their health.

With the place of residence, our study found out that young men from the rural areas had a lesser odd of using tobacco compared to those from the urban centre. This is in line with previous studies $[14,28,29]$. 
The possible explanation may be that urban centres may have higher exposure and accessibility to tobacco in all its forms compared to rural areas.

\section{Strength and Limitations}

There are some limitations to our research worth noting. The sample used was not uniform for all countries. The cross-sectional nature of the DHS data was from the current versions of DHS is SSA countries and this ranged from 2010 to 2018 but social behaviour pattern changes with time. It is also impossible to ascertain temporality of sequence thus, only associations could be assessed but not causality. Nevertheless, the strengths of our findings are entrenched in the standardized study design, thoroughly data collected using standardized methodologies, yielding comparable samples across 21 SSA countries, reflecting a large sample size of 48,885 young men. This is also an erratic look at the young people's usage of tobacco, which is essentially important to understand the consumption of tobacco in SSA.

\section{Conclusion}

We examined the prevalence and the drivers associated with tobacco use among young men in 21 SSA countries. Prevalence of tobacco among young men in the sub-region was slightly below 10 per cent. Nevertheless, this varied across SSA countries with the lowest prevalence among young men from Ghana and highest among those from Lesotho. Age, level of education, wealth status, working status, marital status, religion and place of residence were seen to have a statistically significant association with tobacco use among young men in SSA. Consequently, these socioeconomic factors should be considered when trying to tackle tobacco use in SSA. Specific public health interventions should take into account these socio-economic factors to reduce tobacco use among young people in SSA.

\section{Abbreviations}

AOR=adjusted odds ratios; Cl: Confidence Intervals; COR: Crude Odds Ratios; DHS: Demographic and Health Survey; SDG: Sustainable Development Goals; SSA: sub-Saharan Africa

\section{Declarations}

\section{Acknowledgements}

The authors thank the MEASURE DHS project for their support and for free access to the original data.

\section{Authors' Contributors}

EKMD and AS conceived and designed the study. AS analysed the data. EKMD, AS, KSD, and SY drafted the manuscript. All the authors read the manuscript several times and have given their final approval for 
publication.

\section{Funding}

The authors have no support or funding to report.

\section{Ethics approval and consent to participate}

The DHS surveys obtain ethical clearance from the Ethics Committee of ORC Macro Inc. as well as Ethics Boards of partner organisations of the various countries such as the Ministries of Health. During each of the surveys, either written or verbal consent was provided by the young men. Since the data was not collected by the authors of this manuscript, official permission was sought from MEASURE DHS website and access to the data was provided after our intent for the request was assessed and approved on 3rd April 2019. More details regarding DHS data and ethical standards are available at: http://goo.gl/ny8T6X

\section{Consent for publication}

No consent to publish was needed for this study as we did not use any details, images or videos related to individual participants. In addition, data used is available in the public domain.

\section{Availability of data and materials}

Data for this study were sourced from Demographic and Health surveys (DHS) and available here: http://dhsprogram.com/data/available-datasets.cfm.

\section{Competing interests}

The authors declare that they have no conflict of interest.

\section{Author details}

${ }^{1}$ Department of Population and Health, University of Cape Coast, Cape Coast, Ghana

${ }^{2}$ Faculty of Health Sciences, University of Ottawa, Ottawa, Canada

${ }^{3}$ Warwick Centre for Applied Health Research and Delivery (WCAHRD), Division of Health Sciences, Warwick Medical School, University of Warwick, Coventry, CV4 7AL, UK

\section{References}

1. Siddiqi K, Shah S, Abbas SM, Vidyasagaran A, Jawad M, Dogar O, Sheikh A. Global burden of disease due to smokeless tobacco consumption in adults: analysis of data from 113 countries. BMC medicine. 2015 Dec 1;13(1):194. 
2. Ezzati M, Lopez AD. Estimates of global mortality attributable to smoking in 2000. The lancet. 2003 Sep 13;362(9387):847-52.

3. WHO. Tobacco Factsheet

Regional Office for Africa. 2020

- control access on the 8th April 2020

WHO. Tobacco Factsheet. Regional Office for Africa.2020 https://www.afro.who.int/healthtopic/tobacco - control access on the 8th April 2020.

4. Brigden LW, de Beyer J, editors. Tobacco control policy: strategies, successes, and setbacks. The World Bank; 2003 May 3.

5. Blecher $E$. The impact of tobacco advertising bans on consumption in developing countries. Journal of health economics. $2008 \mathrm{Jul}$ 1;27(4):930 - 42.

6. Sreeramareddy CT, Pradhan PM, Sin S. Prevalence, distribution, and social determinants of tobacco use in 30 sub-Saharan African countries. BMC Med. 2014 Dec;12(1):243.

7. Baker F, Ainsworth SR, Dye JT, Crammer C, Thun MJ, Hoffmann D, Repace JL, Henningfield JE, Slade J, Pinney J, Shanks T. Health risks associated with cigar smoking. Jama. 2000 Aug;9(6):735-40. 284(.

8. Boffetta P, Hecht S, Gray N, Gupta P, Straif K. Smokeless tobacco and cancer. The lancet oncology. 2008 Jul 1;9(7):667 - 75.

9. Warnakulasuriya S, Dietrich T, Bornstein MM, Peidró EC, Preshaw PM, Walter C, Wennström JL, Bergström J. Oral health risks of tobacco use and effects of cessation. International dental journal. 2010 Feb;60(1):7-30.

10. Nketiah-Amponsah E, Afful-Mensah G, Ampaw S. Determinants of cigarette smoking and smoking intensity among adult males in Ghana. BMC public health. 2018 Dec 1;18(1):941.

11. Nyirenda HT, Mulenga D, Silitongo M, Nyirenda HB, Nyirenda T. Spatial distribution and correlates of smoking in Zambia. BMJ open. 2019 Aug 1;9(8):e030044.

12. Doku D, Darteh EK, Kumi-Kyereme A. Socioeconomic inequalities in cigarette smoking among men: evidence from the 2003 and 2008 Ghana demographic and health surveys. Archives of Public Health. 2013 Dec 1;71(1):9.

13. Singh CR, Kathiresan K. Effect of cigarette smoking on human health and promising remedy by mangroves. Asian Pacific journal of tropical biomedicine. 2015 Feb 1;5(2):162-7.

14. Dickson KS, Ahinkorah BO. Understanding tobacco use and socioeconomic inequalities among men in Ghana, and Lesotho. Archives of Public Health. 2017 Dec;1(1):30. 75 (.

15. Santero M, Melendi S, Hernández-Vásquez A, Irazola V. Socio-economic inequalities in smoking prevalence and involuntary exposure to tobacco smoke in Argentina: Analysis of three crosssectional nationally representative surveys in 2005, 2009 and 2013. PloS one. 2019;14(6).

16. Si Y, Zhou Z, Su M, Wang X, Li D, Wang D, He S, Hong Z, Chen X. Socio-Economic Inequalities in Tobacco Consumption of the Older Adults in China: A Decomposition Method. Int J Environ Res Public Health. 2018 Jul;15(7):1466. 
17. Harper S, McKinnon B. Global socioeconomic inequalities in tobacco use: internationally comparable estimates from the World Health Surveys. Cancer Causes \& Control. 2012 Mar 1;23(1):11-25.

18. Corsi DJ, Neuman M, Finlay JE, Subramanian SV. Demographic and health surveys: a profile. International journal of epidemiology. 2012 Dec 1;41(6):1602-13.

19. Seidu AA, Darteh EK, Kumi-Kyereme A, Dickson KS, Ahinkorah BO. Paid sex among men in subSaharan Africa: Analysis of the demographic and health survey. SSM-Population Health. 2019 Oct 18:100459.

20. Banchani E, Tenkorang EY. Determinants of Low Birth Weight in Ghana: Does Quality of Antenatal Care Matter?. Maternal and Child Health Journal. 2020 Feb 5:1-0.

21. Khanal V, Adhikari M, Karki S. Social determinants of tobacco consumption among Nepalese men: findings from Nepal Demographic and Health Survey 2011. Harm reduction journal. 2013 Dec 1;10(1):40.

22. Wang Q, Shen JJ, Sotero M, Li CA, Hou Z. Income, occupation and education: Are they related to smoking behaviours in China?. PloS one. 2018;13(2).

23. Abdulrahim S, Jawad M. Socioeconomic differences in smoking in Jordan, Lebanon, Syria, and Palestine: a cross-sectional analysis of national surveys. PloS one. 2018;13(1).

24. Fernando HN, Wimaladasa IT, Sathkoralage AN, Ariyadasa AN, Udeni C, Galgamuwa LS, Herath $P$, Kumarasinghe N. Socioeconomic factors associated with tobacco smoking among adult males in Sri Lanka. BMC Public Health. 2019 Dec;19(1):778.

25. Ramsey MW Jr, Chen-Sankey JC, Reese-Smith J, Choi K. Association between marital status and cigarette smoking: variation by race and ethnicity. Preventive medicine. 2019 Feb 1; 119:48-51.

26. Wang Z, Koenig HG, Al Shohaib S. Religious involvement and tobacco use in mainland China: A preliminary study. BMC public health. 2015 Dec 1;15(1):155.

27. Garrusi B, Nakhaee N. Religion and smoking: a review of recent literature. The International Journal of Psychiatry in Medicine. 2012 Apr;43(3):279-92.

28. Pampel F. Tobacco use in sub-Sahara Africa: estimates from the demographic health surveys. Social science \& medicine. 2008 Apr 1;66(8):1772-83.

29. Völzke H, Neuhauser H, Moebus S, Baumert J, Berger K, Stang A, Ellert U, Werner A, Döring A. Urbanrural disparities in smoking behaviour in Germany. BMC public health. 2006 Dec 1;6(1):146.

\section{Figures}




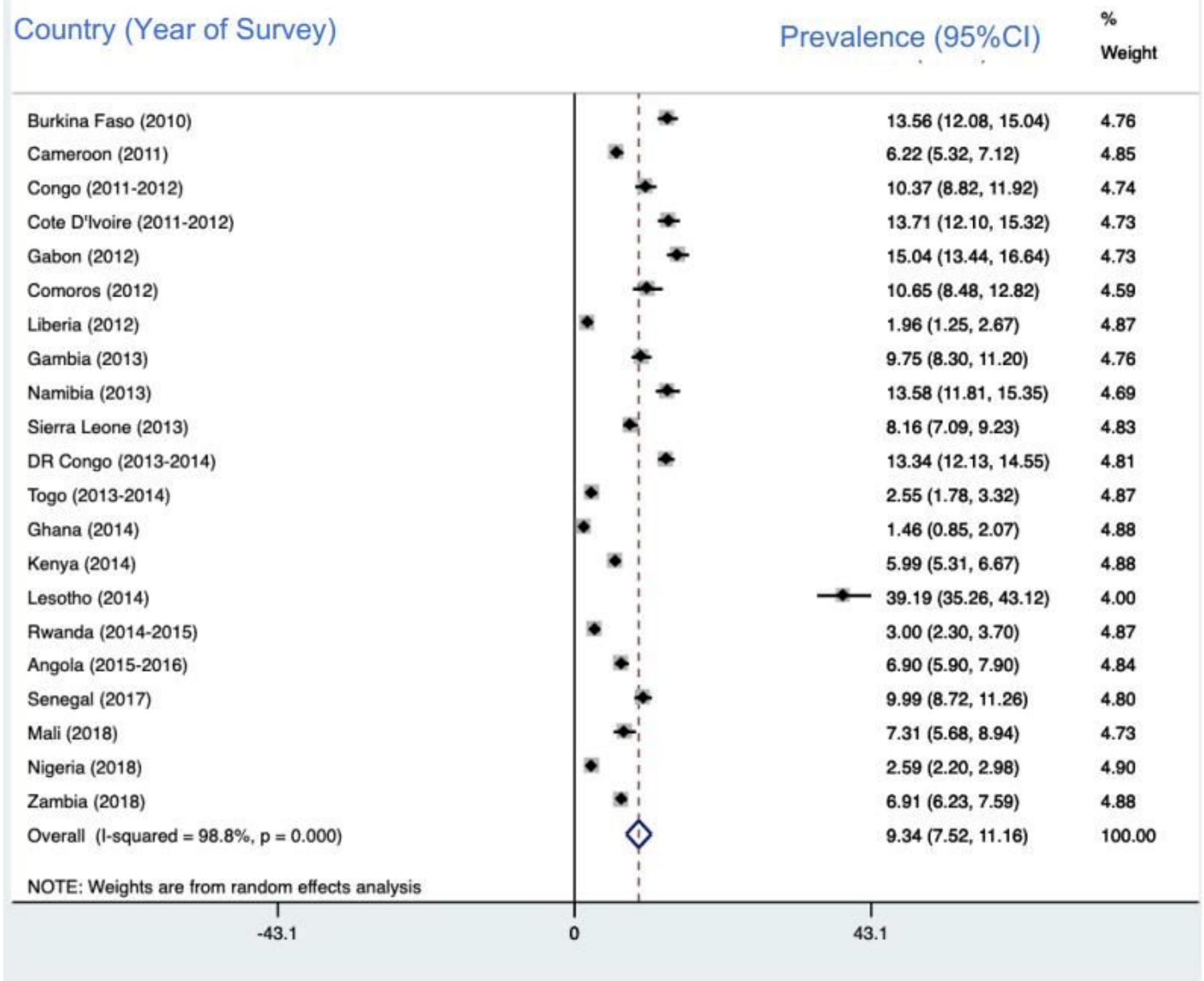

\section{Figure 1}

Prevalence of tobacco use among young men in SSA 